\title{
Occupational Health Risks Associated with Medical Waste Management Practices among Health Professionals Working in Three District Hospitals in Rwanda
}

\author{
Jotham Karenzi ${ }^{1}$, Noel Korukire ${ }^{2 *}$, David Basheija ${ }^{3}$, Innocent Hakizimana ${ }^{3}$, Marie Claire Ineza ${ }^{4}$, Mecthilde
} Mukangendo ${ }^{5}$, Isabelle Kayitesi ${ }^{5}$, Emelyne Umutoni Cishahayo ${ }^{6}$, Liliane Birasa ${ }^{7}$, Charite Niyitegeka ${ }^{2}$, Abela Anne M'Lurhe ${ }^{5}$

${ }^{1}$ School of Public Health, Jomo Kenyatta University of Agriculture and Technology, Kigali, Rwanda

2 School of Public Health, College of Medicine and Health Sciences, University of Rwanda

${ }^{3}$ Centre for language enhancement, College of Social Sciences, University of Rwanda

${ }^{4}$ School of Dentistry, College of Medicine and Health Sciences, University of Rwanda

${ }^{5}$ School of Health Sciences, College of Medicine and Health Sciences, University of Rwanda

${ }^{6}$ School of Nursing and Midwifery, College of Medicine and Health Sciences University of Rwanda

7 American Refugee Committee, Rwanda Program, Kigali, Rwanda

*Corresponding author: Noel Korukire, School of Public Health, College of Medicine and Health Sciences, University of Rwanda, Remera Campus, KG 11 Ave, 47, Kigali, Rwanda. Email: koranoe1980@gmail.com

\begin{abstract}
Background

Proper healthcare waste management is crucial to minimize the exposure of health professionals, patients, and the public in general, and to reduce the pollution of the environment in particular. In Rwanda, scientific documents on occupational health risks resulting from medical waste management practices among healthcare workers are currently rare.
\end{abstract}

Aim

This study aimed to explore occupational health risks associated with medical waste management practices among health professionals in the Rwandan context.

\section{Method}

A cross-sectional study design was used. The study used both quantitative and qualitative methods. The respondents were composed of health professionals (medical doctors, nurses, and paramedical staff) from the district hospital and six key informants. We used questionnaire, interview guide, and observation checklists as research instruments. We performed descriptive statistics to analyze the quantitative data. Also, qualitative data were analyzed using narrative analysis method.

\section{Results}

The findings revealed that $56.5 \%$ of respondents from Kibagabaga hospital, 26.8\% from Masaka and $49.3 \%$ from Muhima Hospital reported that they experienced occupational health risks related to inadequate medical waste management at their workplaces, and some of those risks include risk of infection and physical injuries.

\section{Conclusion}

This study concludes that health professionals working in health facilities in Rwanda are exposed to the risks resulting from poor medical waste management practices. Thus, the study recommends putting more emphasis on raising awareness of staff towards risks resulting from poor medical waste management practices.

Rwanda J Med Health Sci 2019;2(3):252-257.

Keywords: Occupational health risk; Medical waste; Health professionals, Hospital, Healthcare waste

\section{Background}

The Management of healthcare waste in an inappropriate way can be a source of severe diseases to health professionals, patients, waste handlers, and to the general public.[1,2] Literature indicates that healthcare workers are at high risk of getting infections due to their exposure to medical waste, mainly bloodborne pathogens.[3,4] The risks associated with infectious waste generated in healthcare settings are accidental needle stick injuries, which can cause different types of hepatitis and HIV as well.[5] Also, the exposure to harmful chemicals and radioactive waste used in health settings may constitute health hazards to healthcare workers as well as people out of the hospital premises. [6,7]

Equally important, scholars indicate that the operating environment of healthcare professionals is one of the most significant risky occupational areas.[8,9] A study conducted in India in 2001 on needle stick injuries 
among healthcare workers in tertiary care hospital indicated that $59 \%$ of respondents reported having occupational exposure to blood and body fluid in the year preceding the study, and $50 \%$ of nurses and 25.9 $\%$ of resident doctors had exposure to blood and body fluid.[9] Also, studies conducted in Portugal and Iran indicated that healthcare professionals are exposed to health hazards from medical waste. For instance, a study conducted in Portugal suggests that $23.4 \%$ of nurses and $12 \%$ of doctors experienced accidental injuries during patient care procedures. These accidents were linked to improper healthcare waste management. This study showed that $83 \%$ of nurses had a high risk of being in contact with medical waste, and the risk of infection due to injuries from sharp waste was high.[10] Another study done among health professionals in a Teaching Hospitals in Tehran on occupational exposure to hazardous waste such as blood and body fluids indicated that more than $60.3 \%$ of the respondents confirmed their exposure to the risks related to medical waste.[11]

A study conducted in Kenya indicated that 20\% of medical waste regenerated in Nairobi posed a challenge of high potential injuries and infection among medical waste handlers.[12] The same study indicated that accidents related to biomedical waste management were linked to insufficient knowledge towards waste categorization at point of production, inattention to directives and rules pertaining medical waste management, inadequate training, cognizance, inappropriate legal framework and policy enforcement related to waste handling, and the insufficient knowledge on waste categories and processing of medical waste. [12] Literature showed that inadequate segregation of biomedical waste exposed healthcare staff and waste handlers as well as administration staff.[13]

In Rwanda, health care facilities across 30 districts of the country, including the referral hospitals, generate large quantities of medical waste. It is estimated that 4,171 tons of healthcare waste are produced annually, and this increase is projected to the rate of 5\% per annum.[14] In 2014, a report the Ministry of Health highlighted some weakness in medical waste management such as the absence of plans towards hospital medical waste management; lack of regulatory framework among others.

To prevent the hazards and risks associated with medical waste management practices among health professionals, patients, and the general public, the Ministry of Health $(\mathrm{MoH})$ in Rwanda, established guidelines and standards of procedures for proper medical waste management. Also, the $\mathrm{MoH}$ has been organizing training related to medical waste management to reduce those hazards and risks. However, there is little evidence showing the occupational health risks connected to medical waste practices among health professionals in hospitals in Rwanda. The lack of this information may accelerate the exposure of health care workers to those risks. It may also be a barrier to the achievement of sustainable development goals, especially goal six, which draws attention to clean water and sanitation.[15] This study, therefore, aimed at exploring the occupational health risks linked to medical waste management practices among health professionals of selected hospitals in Rwanda. The following research questions were formulated to guide this study:

- What quantity of medical waste is generated daily in three selected hospitals?

- What are the practices of health professionals that expose them to the risk from medical waste?

- How many cases of occupation health risks occurred among health professionals due to inadequate medical waste management?

- Which groups of health professionals are highly exposed to the occupational health risk among health professionals of selected hospitals?

\section{Methods}

This study was conducted in three selected district hospitals, namely Muhima, Kibagabaga, and Masaka Hospital. A cross-sectional study design using both qualitative and quantitative methods was applied. The study was quantitative, especially to quantify the occupational accidents that occurred. It was also qualitative to observe some practices towards medical waste segregation and the use of personal protective equipment as well.

The study population of this study was composed of 532 health professionals (physicians, nurses and paramedicals) working in the hospitals mentioned above. A purposive sampling technique was used to select the three district hospitals and key six informants such as hospital administrator and environmental health professionals as well. Also, a simple random sampling was used to calculate the total sample size of the study. The overall sample size was 228 . This sample was made of 88 study participants representing Kibagabaga hospital, 69 from of Muhima, and 71 from Masaka hospital.

Since the number of nurses, medical doctors, and paramedicals is different in all selected hospitals, proportionate sampling technique was used to have a representative sample for each group of staff in each hospital. Therefore, Muhima hospital was represented by 4 medical doctors, 50 nurses and 15 paramedical staff. Masaka hospital was represented by 7 medical doctors, 47 nurses and 17 paramedical staff. Kibagabaga was represented by 8 medical doctors, 59 nurses, and 20 paramedical staff. Moreover, a systematic sampling technique was used to determine precisely the staff (depending on the interval) that would participate according to the list of staff in each category. After having the record from the department of Human resources, the starting point was a staff appearing as the first person on the list.

Questionnaires with close-ended and open-ended questions were used as data collection instrument. 
This questionnaire was adopted from similar studies conducted in similar settings. Also, the semi-structured interview guide was developed and used to collect data from the informants, especially data related to the budget allocated to medical waste management as well as reporting the accidents resulting from medical waste management practices. Moreover, observation checklist also was used to observe some practices related to medical waste segregation. The response rate was $98.6 \%$. Face to face data collection was assisted by enumerators. After collecting data, questionnaires were reviewed to check if they were complete. For quantitative data, coding, entry, and analysis were conducted using the Statistical Package for the Social Sciences (SPSS). The analysis of quantitative data was limited to descriptive statistics. Also, qualitative data were analysed using narrative method which focused on reporting what respondents said.

Researchers obtained ethical clearance from the Institutional Review Board of the University of Rwanda. Research ethics committees of the selected hospitals also provided permissions for data collection.
After getting the ethical clearance from the university and authorisation from hospitals'management, the researcher organized the training of enumerators and explained to them the purpose of the study, all study information and data collection procedures as well. Respondents got explanations about the purpose of the research as well as the confidentiality and anonymity of their responses. Moreover, respondents were informed about the minimum risk of the study as well as their right to participate and withdraw from the study any time, or for any reason, and without any consequence. Respondents were asked to participate in this study by signing the consent form voluntarily.

\section{Results}

Socio-demographic characteristics of respondents Table 1 shows that $81.4 \%$ at Muhima; $58.2 \%$ at Masaka, and $34.1 \%$ at Kibagabaga hospital have a working experience of less than 5 years. $70.4 \%$ at Muhima ; $41.2 \%$ at Kibagabaga and $63.8 \%$ of respodents have advanced diploma.

Table 1. Socio-demographic characteristics of respondents

\begin{tabular}{|c|c|c|c|c|c|c|}
\hline \multirow{2}{*}{$\begin{array}{l}\text { Variables } \\
\text { Category of staff }\end{array}$} & \multicolumn{2}{|c|}{$\begin{array}{l}\text { Muhima } \\
\text { hospital }\end{array}$} & \multicolumn{2}{|c|}{ Kibagabaga Hospital } & \multicolumn{2}{|c|}{$\begin{array}{l}\text { Masaka } \\
\text { Hospital }\end{array}$} \\
\hline & $\mathrm{N}$ & $\%$ & $\mathrm{~N}$ & $\%$ & $\mathrm{~N}$ & $\%$ \\
\hline Medical doctor & 7 & 9.9 & 8 & 9.4 & 7 & 9.9 \\
\hline Nurse & 40 & 56.3 & 51 & 60 & 40 & 56.3 \\
\hline Midwives & 12 & 16.9 & 8 & 9.4 & 12 & 16.9 \\
\hline Paramedical & 12 & 16.9 & 18 & 21.2 & 12 & 16.9 \\
\hline Total & 71 & 100 & 85 & 100 & 69 & 100 \\
\hline \multicolumn{7}{|l|}{ Level of education } \\
\hline Master & 0 & 0 & 0 & 0.00 & 1 & 1.4 \\
\hline Bachelor & 21 & 29.6 & 28 & 32.9 & 16 & 23.2 \\
\hline Advanced diploma & 50 & 70.4 & 35 & 41.2 & 44 & 63.8 \\
\hline Secondary & 0 & 0.0 & 22 & 25.9 & 8 & 11.6 \\
\hline Total & 71 & 100 & 85 & 100 & 69 & 100 \\
\hline \multicolumn{7}{|l|}{ Work experience } \\
\hline Less than 5 years & 57 & 81.4 & 28 & 34.1 & 39 & 58.2 \\
\hline 5 years- 10 years & 11 & 15.7 & 40 & 48.8 & 20 & 29.9 \\
\hline 10 years and above & 2 & 2.9 & 14 & 17.1 & 8 & 11.9 \\
\hline Total & 70 & 100 & 82 & 100 & 67 & 100 \\
\hline
\end{tabular}

Quantity of medical waste generated daily in three hospitals

Table 2 indicates the amount of hazardous waste generated in these hospitals $(0.57 \mathrm{~kg} /$ capita/day in hospital A; $0.28 \mathrm{~kg} /$ capita/day in hospital B; and $0.36 \mathrm{~kg} /$ capita/day in Hospital C). However, this quantity is an estimate done by a responsible person in charge of environmental health, since there is no system of quantifying the waste generated daily. Also, a small quantity of waste with a high content of heavy metals is produced. 
Table 2. Quantity of waste generated in three hospitals

\begin{tabular}{lccc}
\hline Types of medical waste produced (in Kg/capita/day) & Muhima Hospital & $\begin{array}{c}\text { Kibagabaga } \\
\text { Hospital }\end{array}$ & $\begin{array}{c}\text { Masaka } \\
\text { Hospital }\end{array}$ \\
\hline Infectious waste & 0.57 & 0.28 & 0.36 \\
General waste & 1.42 & 0.72 & 0.82 \\
Pathological waste & 0.14 & 0.07 & 0.11 \\
Radioactive waste & 0.02 & 0.00 & 0.01 \\
Sharps & 0.02 & 0.01 & 0.01 \\
Pharmaceutical waste & 0.01 & 0.00 & 0.00 \\
Chemical waste & 0.10 & 0.00 & 0.03 \\
Waste with a high content of heavy metals & 0.00 & 0.00 & 0.00 \\
Total & 2.28 & 1.08 & 1.34 \\
\hline
\end{tabular}

Practices that expose health professionals to the risks of medical wastes

Key informants from these hospitals mentioned that health professionals sometimes did not comply with the protocol of medical waste management. The hospitals provide materials and equipment to deal with medical waste, but in some cases, some healthcare workers do not use those materials and equipment. This results in a different kind of exposure to occupational hazards in different circumstances.

P1\&P2 said: “: Some cases of misuse of the safety boxes, improper use of personal protective equipment by some staff members expose bealth professionals and waste workers to the risk of infections, risk of physical injuries and another form of occupational health riskes." Also, data collectors observed some weaknesses in compliance with medical waste management protocol, particularly in waste segregation where coding and colors of waste bags were not respected.
Occurrence of occupational health risks among health professionals in hospitals

Table 3 shows that experienced occupational health risks are at a high level in two hospitals. 56.6\% in hospital A and $49.3 \%$ in-hospital C while the rate is lower in-hospital B equal to $26.8 \%$. A key informant (P1) from one of these hospitals confirmed the probability of occurrence of these occupational risks due to inadequate medical waste management and said: "Cases of accidents / physical injuries may occur in our hospital." The study also revealed that risks of physical injuries, risk of infections tended to be the leading occupational health risks to take place in these hospitals. P2 confirmed that, due to the absence of a reporting system, occupational health risk might be more. S/he declared: "since we do not have a reporting system regarding these occupational health risks, they are probably many, but we do not exactly know every risk that occurs."

Table 3. The occurrence of occupational health risk

\begin{tabular}{lcccccc}
\hline $\begin{array}{l}\text { Have you experienced } \\
\text { occupational health risk at } \\
\text { the workplace? }\end{array}$ & \multicolumn{2}{c}{$\begin{array}{c}\text { Muhima } \\
\text { hospital }\end{array}$} & \multicolumn{2}{c}{ Kibagabaga Hospital } & \multicolumn{2}{c}{$\begin{array}{c}\text { Masaka } \\
\text { Hospital }\end{array}$} \\
\cline { 2 - 7 } Yes & $\mathrm{N}$ & $\%$ & $\mathrm{~N}$ & $\%$ & $\mathrm{~N}$ & $\%$ \\
No & 48 & 56.5 & 19 & 26.8 & 34 & 49.3 \\
I do not know & 34 & 40.0 & 46 & 64.8 & 31 & 44.9 \\
Total & 03 & 3.5 & 05 & 8.5 & 04 & 5.8 \\
\hline Types of occupational health & $\mathbf{8 5}$ & $\mathbf{1 0 0}$ & $\mathbf{7 1}$ & $\mathbf{1 0 0}$ & $\mathbf{6 9}$ & $\mathbf{1 0 0}$ \\
Infection & 21 & 43.8 & 04 & 21.1 & & \\
Trauma & 07 & 14.6 & 03 & 15.8 & 05 & 44.2 \\
Physical injury & 20 & 41.7 & 12 & 63.2 & 13 & 38.2 \\
Fire & 00 & 0.0 & 00 & 0.0 & 00 & 0.0 \\
Radioactivity & 00 & 0.0 & 00 & 0.0 & 00 & 0.0 \\
Chemical & 00 & 0.0 & 00 & 0.0 & 01 & 2.9 \\
Total & $\mathbf{4 8}$ & $\mathbf{1 0 0}$ & $\mathbf{1 9}$ & $\mathbf{1 0 0}$ & $\mathbf{3 4}$ & $\mathbf{1 0 0}$ \\
\hline
\end{tabular}




\section{Groups of health professionals that are highly exposed to occupational health risks}

Several respondents in qualitative data confirmed that healthcare workers in maternity and injection departments are at high risk of exposure compared to other healthcare staff. P4, P5, \& P20 argued: "Staff from the maternity department are highly exposed to health risks compared to others." P5 said: "People from injection services are also at high risk." P7 indicated that maternity healthcare workers are highly exposed due to methods of evacuating body fluids and inadequate training on waste management.

The P111 indicated that some nurses do not separate medical wastes. He/she said: "For nurses when no segregation is done, they can injure themselves." P122 said: "Midwives have contacts with several infected body wastes." P123 indicated that midwives work in very infective conditions with inadequate protective measures. In brief, poor segregation of waste, insufficient knowledge, and skills on waste management, lack of appropriate protective equipment in some departments, and overworking that leads to stress and extreme fatigue were mentioned as factors that expose health care workers to occupational health risks associated with medical waste management practices.

\section{Discussion}

The findings from this study revealed that the high quantity of waste generated is a non-hazardous waste. These findings are in line with the standards of the World Health Organization and other scholars which indicate that up to $80 \%$ of the total waste generated in the health care facilities are general waste, and $20 \%$ remaining are classified into hazardous medical waste.[16,17] Also, the findings of this study illustrated the lack of a system of quantification of medical waste generated. These findings are also in line with another study conducted by Dasimah Omar et al. which showed that, in three hospitals (Tumpat, Batu Pahat and Taiping), they did not know the quantity of wastes that were generating daily.[18,19] However, this lack of information related to the exact amount of waste generated in a health care facility is an indicator of weakness in medical waste management, and this may have negative effects on planning towards appropriate medical waste management, and minimization of occupational health risks among health professionals working in health care settings and waste workers as well.

The findings of this study also pointed out some poor practices regarding waste management in the study area, especially the separation of waste. Result illustrated that some healthcare workers sometimes do not comply with protocol in the context of medical waste separation. This finding is in line with other studies where scholars revealed weaknesses in healthcare waste segregation compared to the definite rules and standards where adherence to the standards is at a lower level.[7,19,20] Therefore, with inappropriate medical waste separation in hospitals, healthcare workers expose not only themselves but also waste handling workers to infections, injuries, and other occupational risks.[17] Commenting on this poor separation of waste, it might be linked to the lack of awareness particularly for new staff regarding risks associated with medical waste as indicated by scholars where health care workers in different countries do not have much knowledge about the risks related to hazardous waste generated in healthcare settings.[1]

Findings of the study showed that the risk of physical injuries and risks of infections represent a high probability of health threat associated with medical waste management practices. These findings confirm another study which indicated that the likelihood of injuries was high in public hospitals.[21] Those health workers who deal directly with patients, including nurses, are the ones that are highly exposed to occupational health risks associated with poor healthcare waste management practices.[21] Also, findings of this study pointed out that nurses, especially those working in injection and maternity departments, make a group of healthcare workers at risks of getting injuries from sharp medical wastes. This finding is in line with other studies that indicated nurses and operating room technicians as the ones who have a high risk of physical accidents resulting from injections compared to others.[22] This high exposure should be linked to the fact that these nurses and midwives are the ones who execute what has been prescribed by medical doctors such as injections, bandage, cleaning wounds, among others.

\section{Limitations}

Limitations of this study include the fact that these findings cannot be generalized to all clinical settings in the country since the study was conducted in three public hospitals. Also, the quantity of waste mentioned in this study is an estimate, not the real amounts.

\section{Conclusion}

This study aimed at exploring occupational health risks associated with healthcare waste management among health professionals of three district hospitals in Rwanda. The study concludes that healthcare workers in the three investigated public hospitals do not comply with protocol, and this inability exposes health professionals and the public to the occupational health risks. Some cases of occupational health accidents among healthcare workers in Rwanda occur but are not reported as there is no formal system of reporting occupational health accidents associated with medical waste. The study recommends that healthcare staff must comply with the protocol in the context of medical waste management. Another recommendation calls for the mobilization regarding healthcare waste management among health professionals to minimize occupational health risks. 
This study also advocates for the establishment of an occupational health risk reporting system to have data on occupational health risks occurrence and take preventive measures accordingly.

\section{Acknowledgment}

Our gratitude goes to the management of all hospitals (Muhima,Kigabagabaga, and Masaka) for facilitating this study.

\section{Conflict of interest}

All authors report no conflict of interest.

\section{Authors' contribution}

J.K was responsible for the study conception and design and data analysis. N. K, M.C.I, M.M,E.U.C, I. K, L.B, and C.N contributed in searching the literature to support the analysis and data interpretation while D.B and I.H,contributed to the drafting, proofreading as well as editing of the manuscript.

This article is published open access under the Creative Commons Attribution-NonCommercial NoDerivatives (CC BY-NC-ND4.0). People can copy and redistribute the article only for noncommercial purposes and as long as they give appropriate credit to the authors. They cannot distribute any modified material obtained by remixing, transforming or building upon this article. See https://creativecommons.org/ licenses/by-nc-nd/4.0/

\section{References}

1. Dipak DJ. Review on the diseases caused due to improper handling of Biomedical Waste. 2016;4:98-100.

2. Babanyara YY, Ibrahim DB, Garba T, Bogoro AG, Abubakar MY. Poor Medical Waste Management ( MWM ) Practices and Its Risks to Human Health and the Environment : A Literature Review. 2013. p. 757-64.

3. Butsashvili M, Kamkamidze G, Kajaia M, Morse DL, Triner W, Dehovitz J, et al. Occupational exposure to body fluids among health care workers in Georgia. Occup Med (Chic Ill). 2012;62:620-6.

4. Jaybhaye D, Dahire P, Nagaonkar A, Vedpathak V, Deo D, Kawalkar U. Needle stick injuries among health care workers in tertiary care hospital in tertiary care hospital of rural India. Int J Med Sci Public Heal. 2014;3:49.

5. Amsalu A, Worku M, Tadesse E, Shimelis T. The exposure rate to hepatitis $\mathrm{B}$ and $\mathrm{C}$ viruses among medical waste handlers in three government hospitals, southern Ethiopia. Epidemiol Health. 2016;38:e2016001.

6. Tait FN, Mburu C, Gikunju J. Occupational safety and health status of medical laboratories in Kajiado county, Kenya. Pan Afr Med J. 2018;29:1-17.

7. Muluken A, Haimanot G, Mesafint M. Healthcare waste management practices among healthcare workers in healthcare facilities of Gondar town, Northwest Ethiopia. Heal Sci J. 2013;7:315-26.
8. Ndejjo R, Musinguzi G, Yu X, Buregyeya E, Musoke D, Wang JS, et al. Occupational Health Hazards among Healthcare Workers in Kampala, Uganda. J Environ Public Health. 2015;2015.

9. Triolo PK. Occupational health hazards of hospital staff nurses. Part II: Physical, chemical, and biological stressors. AAOHN J. 1989;37:274-9.

10. Rutala WA, Weber DJ. Infectious waste - mismatch between science and policy. $\mathrm{N}$ Engl $\mathrm{J}$ Med. 1991;325:578-82.

11. Malekahmadi F, Yunesian M, Yaghmaeian K, Nadafi K. Analysis of the healthcare waste management status in Tehran hospitals. J Environ Heal Sci Eng. 2014;12:1-5.

12. Nguthu MM, K GJ, Justus OM, Joseph W. Occupational Safety and Health Accidents among Biomedical Waste Handlers in Nairobi County. 2016;6:8-17.

13. Shareefdeen ZM. Medical Waste Management and Control. J Environ Prot (Irvine, Calif). 2012;03:1625-8.

14. Obadia B. Performance Audit Report of the Auditor General on Health Care Waste Management At Referral Hospitals in Rwanda. 2014;

15. Derek Osborn, Amy Cutter FU. Universal Sustainable Development Goals: Report of a Study by Stakeholder Forum. 2015;

16. Coker A, Sangodoyin A, Sridhar M, Booth C, Olomolaiye P, Hammond F. Medical waste management in Ibadan, Nigeria: Obstacles and prospects. Waste Manag. 2009. p. 804-11.

17. Ministry of Health Kenya. Health SectorPerformance Report July 2008 - June 2009. 2010;2009:xv.

18. Omar D, Nazli SN, Karuppannan SA. Clinical Waste Management in District Hospitals of Tumpat, Batu Pahat and Taiping. Procedia - Soc Behav Sci [Internet]. Elsevier B.V.; 2012;68:134-45. Available from: http://dx.doi.org/10.1016/j.sbspro.2012.12.213

19. Abor PA, Bouwer A. Medical waste management practices in a Southern African hospital. Int J Health Care Qual Assur. 2008;21:356-64.

20. Njue PM, Cheboi KS, Shadrak O. Adherence to Healthcare Waste Management Guidelines among Nurses and Waste Handlers in Thika Sub-countyKenya. Ethiop J Health Sci. 2015;25:295-304.

21. Sefouhi L, Kalla M, Bahmed L, Aouragh L. The Risk Assessment for the Healthcare Waste in the Hospital of Batna City, Algeria. Int J Environ Sci Dev. 2013;442-5.

22. Dement JM, Epling C, Ostbye T, Pompeii LA, Hunt DL. Blood and body fluid exposure risks among health care workers: Results from the Duke health and safety surveillance system. Am J Ind Med. 2004;46:637-48. 